\title{
Incidental occult carcinomas in total thyroidectomy for benign diseases of the thyroid
}

\author{
Ranil Fernando', D S G Mettananda'1, and L Kariyakarawana' \\ (Index words: total thyroidectomy, incidental carcinoma)
}

\begin{abstract}
Background Total thyroidectomy is increasingly recognised as the preferred surgical option for benign diseases of the thyroid. One factor contributing towards this change in policy is reports of incidental carcinomas in the resected specimens.

Methods This was a prospective study of patients, who underwent total thyroidectomy for benign diseases of the thyroid at the University Surgical Unit, Colombo North Teaching Hospital from January 2003 to December 2005.

Results There were 68 patients ( 67 females) aged 28 to 67 years (mean $44.2(S D=11.1)$. In $6(8.8 \%)$ patients, histological examination of the post-operative specimen showed incidental carcinomas: 2 papillary, 2 medullary and 2 follicular carcinomas. There was no significant difference in age, clinical presentation and functional thyroid status of patients with incidental carcinomas and those with histologically confirmed benign diseases.
\end{abstract}

Conclusions Occurrence of incidental thyroid cancers was $8.8 \%$ in this series, and they were difficult to predict pre-operatively. The policy of performing total thyroidectomy for benign disease of the thyroid obviates the need for further surgery if an incidental carcinoma is found.

\section{Introduction}

Goitre is the most common endocrine disorder encountered by surgeons. The prevalence of goitre worldwide is about 5\% according to the World Health Organization [1]. Benign disease is the main cause of thyroid enlargement. The common benign diseases encountered are multinodular goitres, Graves disease, Plummer's disease and thyroiditis. Some of these patients require surgical intervention.

Total thyroidectomy is increasingly gaining recognition as the preferred surgical option for benign diseases of the thyroid. This change in management of benign thyroid diseases is due to several reasons. One important reason is reports of incidental carcinomas in resected specimens. Several series have reported incidental carcinomas in $6-10 \%$ of thyroids removed surgically [2-5]. The existence of these cancers was not suspected pre- or intra-operatively.

We investigated the occurrence of incidental carcinoma in patients who underwent total thyroidectomy for apparently benign disease of the thyroid.

\section{Materials and methods}

This was a prospective study of patients who underwent total thyroidectomy by a single surgeon for apparently benign diseases of the thyroid at the University Surgical Unit of the Colombo North Teaching Hospital, Ragama, from January 2003 to December 2005. Patients were recruited after obtaining informed consent and patients who had any suspicion of malignancy in the thyroid pre- or intra-operatively were excluded from the study. Details of clinical features, pre-operative investigations, post-operative complications and histological findings were recorded.

Goitres were clinically differentiated into diffuse, multinodular or uninodular. Functional thyroid status was assessed both clinically and biochemically by hormonal assays and classified as hyperthyroid, euthyroid or hypothyroid. Details of pre-operative fine needle aspiration cytology (FNAC) and histological examination of the post-operative specimen performed by a consultant pathologist were recorded. Any intra- or post-operative complications were also noted. Data was analyzed using the computer package SPSS 11.0 for Windows.

Ethical approval for the study was obtained from the Ethics Committee of the Faculty of Medicine, University of Kelaniya.

\section{Results}

Sixty eight patients ( 67 females) who underwent total thyroidectomy for apparently benign diseases were included in the study. They were 28 to 67 years of age (mean $44.2 \mathrm{y}$, SD 11.1y).

Fifteen $(22.1 \%)$ patients had diffuse goitres and 53 $(77.9 \%)$ had multinodular goitres. None had uninodular goitres. Twenty-nine (42.6\%) were clinically and bio-

${ }^{1}$ Department of Surgery, Faculty of Medicine, University of Kelaniya, Ragama, Sri Lanka.

Correspondence: RF, e-mail: <ranilfern@sltnet.lk>. Received 25 July 2008 and revised version accepted 7 December 2008. Competing interests: none declared. 
chemically euthyroid and 39 (57.4\%) were hyperthyroid. None of the patients were hypothyroid. All patients underwent FNAC before surgery and were reported as having benign diseases. Indications for surgery are given in Table 1 . Post-operatively $4(5.8 \%)$ patients developed transient hypocalcaemia and 3 (4.4\%) developed transient hoarseness. None of the patients developed long term complications.

\section{Table 1. Indications for thyroidectomy in the study population}

\begin{tabular}{lcr}
\hline Indication & $\begin{array}{c}\text { Number of subjects } \\
(n=68)\end{array}$ & $(\%)$ \\
\hline Multinodular toxic goitre & 32 & 47.1 \\
Multinodular non-toxic goitre & 20 & 29.4 \\
Thyrotoxicosis & 9 & 13.2 \\
Graves disease & 3 & 4.4 \\
Colloid goitre & 3 & 4.4 \\
Thyroiditis & 1 & 1.5 \\
Total & $\mathbf{6 8}$ & $\mathbf{1 0 0 . 0}$ \\
\hline
\end{tabular}

In $6(8.8 \%)$ patients, histological examination of the post-operative specimen showed incidental carcinomas: $2(33.3 \%)$ papillary carcinomas, $2(33.3 \%)$ medullary carcinomas and $2(33.3 \%)$ follicular carcinomas of the thyroid. There were no statistically significant differences in age, clinical presentation and functional thyroid status of patients with incidental carcinomas and those with histologically confirmed benign diseases. The only male subject in the study had an incidental medullary carcinoma. Comparison of the pre-operative diagnosis and postoperative histological diagnosis of incidental carcinomas is shown in Table 2.

\section{Table 2. Diagnostic details of incidental thyroid carcinomas $(n=6)$}

\begin{tabular}{|c|c|c|}
\hline $\begin{array}{l}\text { Pre-operative } \\
\text { diagnosis }\end{array}$ & & $\begin{array}{c}\text { Post-operative histological } \\
\text { diagnosis }\end{array}$ \\
\hline & $\begin{array}{l}\text { Papillary } \\
\text { carcinoma }\end{array}$ & $\begin{array}{l}\text { Medullary Follicular } \\
\text { carcinoma } \\
\text { carcinoma }\end{array}$ \\
\hline
\end{tabular}

\begin{tabular}{lccc}
\hline $\begin{array}{l}\text { Primary } \\
\text { thyrotoxicosis }\end{array}$ & - & - & 1 \\
$\begin{array}{l}\text { Secondary } \\
\text { thyrotoxicosis }\end{array}$ & 1 & - & - \\
$\begin{array}{l}\text { Multinodular } \\
\text { non-toxic goitre }\end{array}$ & 1 & 1 & 1 \\
Thyroiditis & - & 1 & - \\
Total & $\mathbf{2}$ & $\mathbf{2}$ & $\mathbf{2}$ \\
\hline
\end{tabular}

\section{Discussion and conclusions}

Total thyroidectomy is now increasingly accepted as a preferred surgical option for benign thyroid diseases. It is performed routinely in many centres worldwide. In the last decade some centres in Sri Lanka have also adopted this practice. Several studies have shown a number of advantages of total thyroidectomy over the conventional sub-total thyroidectomy. The main advantage is that it eliminates the risk of recurrence of benign goiter, which is reported to be as high as $42 \%$ following subtotal thyroidectomy [6]. It is widely accepted that a re-operation of the thyroid is a hazardous procedure that is reported to have a high incidence of complications; following a second intervention, the incidence of temporary recurrent laryngeal nerve palsy is $15-23 \%$ and permanent recurrent laryngeal nerve palsy is $2.6-15.5 \%$ [7]. The main disadvantage of total thyroidectomy is the theoretical risk of an increased rate of complications. But several studies have shown that there is no significant difference in either transient and permanent complications following total or subtotal thyroidectomy $[2,4]$.

In this series of patients who underwent total thyroidectomy there was a fairly high $(8.8 \%)$ incidence of incidental carcinomas. This is comparable with results of previous studies which have reported incidences ranging from $6 \%$ to $10 \%$ [2-5]. Our cancers were found in various types of apparently benign goitres. There was no significant difference in age, clinical presentation of goitre or thyroid status between patients with incidental cancers and patients who did not have cancers. Our findings confirm the results of previous studies where incidental carcinomas occurred in all clinical presentations of goitres - both toxic and non-toxic, diffuse, multinodular or uninodular goitres. This makes it very difficult to predict the risk of malignancy in these cases $[5,8,9]$. Histological examination of resected specimens confirmed three main types of thyroid carcinomas occurring as incidental cancers (the exception was the highly malignant anaplastic variant). FNAC did not show any suspicion of malignancy in these six cases.

As our patients with incidental cancers had undergone total thyroidectomy, it obviated the need for a more cumbersome second operation. Sub-total thyroidectomy also carries a risk of cutting into an incidental cancer and disseminating tumour cells. As incidental carcinomas are difficult to predict preoperatively, total thyroidectomy should be the preferred surgical option for treatment of benign goitres.

\section{References}

1. Gaitan E, Nelson NC, Poole GV. Endemic goitre and endemic thyroid disorders. World Journal of Surgery 1991; 15: 205-6.

2. Colak T, Akca T, Kanik A, Yapici D, Aydin S. Total versus sub-total thyroidectomy for the management of benign multinodular goitre in endemic region. Australia New Zealand Journal of Surgery 2004; 74: 974-8. 


\section{Papers}

3. Mishra A, Agarwal A, Agarwal G, Mishra SK. Total thyroidectomy for benign thyroid disorders in an endemic region. World Journal of Surgery 2001; 25: 307-10.

4. Giles Y, Boztepe H, Terzioglu T, Tezelman S. The advantage of total thyroidectomy to avoid re-operation for incidental thyroid cancers in multinodular goitre. Archives of Surgery 2004; 139: 179-82.

5. Lin Ch, Chiang FY, Wang LF. Prevalence of thyroid cancer in hyperthyroidism treated by surgery. Kaohsiung Journal of Medical Sciences 2003; 19: 379-84.

6. Rodjdmark J, Jarhult J. High long-term recurrence rate after subtotal thyroidectomy for nodular goitres. European Journal of Surgery 1995; 161: 725-7.

7. Reeve T, Delbrodge L, Brady P, Crummer P, Smyth C. Secondary thyroidectomy: a twenty year experience. World Journal of Surgery 1988; 12: 449-53.

8. Bapat RD, Pai P, Shah S, Bhandarkar SD. Surgery for thyroid goitre in western India: a prospective analysis of 334 cases. Journal of Postgraduate Medicine 1993; 39: 202-4.

9. Gabriele R, Letizia C, Borghese M, De Toma G, Celi M, et al. Thyroid cancer in patients with hyperthyroidism. Hormone Research 2003; 60: 79-83. 